\title{
Social Problems Facing Poor Women: A Study on Women Benefiting from the Aid Fund in the Ruwaished Area
}

\author{
Raghda Al-Azzeh ${ }^{1}$ Prof. Ismail Al-Zyoud ${ }^{2}$ \\ 1. Faculty of Arts, University of Jordan, Amman, Jordan \\ 2. Faculty of Arts University of Jordan, Amman, Jordan \\ * E-mail of the corresponding author: Raghda. mousa@yahoo.com
}

\begin{abstract}
The study aimed to identify the social problems facing poor women related to themselves, their family, society and gender, and the extent of variation in the answers according to social and economic characteristics. AlRuwaished area is considered one of the poorest regions according to government studies of poverty pockets in Jordan, and they numbered (164) women according to the records of the National Aid Fund for the year 2019 and the descriptive statistics (percentages) were used and an analysis was used. Multiple Analysis of Variance (MANOVA test) variation.

The study reached a number of results, the most important of which are:

The social problems of poor women who head their families, who are beneficiaries of the National Aid Fund in the Ruwaishid region, ranged between (3.46 and 3.43), where the problems generally have a total arithmetic average of (3.45), which is from the middle level, and it came in The first rank is both (problems facing poor women related to themselves, and problems facing poor women related to the family), and these two dimensions have the highest arithmetic average of (3.46) and a standard deviation (0.65 and 0.67), respectively, and they are from the middle level, and secondly The problems faced by poor women related to society $\mathrm{P}$ and gender, with an mean of (3.43) and a standard deviation (0.65), which is of the mean level.
\end{abstract}

Key words: poor women, social problems, national aid fund

DOI: $10.7176 / J L P G / 94-20$

Publication date: February $29^{\text {th }} 2020$

\section{The study Problem:}

Poverty is one of the most important challenges facing societies in the world, as many social, economic and health problems are reflected under it, which are reflected in the nature of the family and its members. One of the most affected by poverty is women, where they are the focus of family life, and the consequences of social problems and their effects will negatively affect its giving and social roles that will affect Her marital and family life and raising her children will cost society a lot in spending on the consequences of those effects instead of spending in the area of developing and developing the country

The problem of poverty remains the most important problem at the level of societies as poor women undergo unbalanced burdens of limited financial capabilities, which increases the severity of the problem of poverty among women, high levels of unemployment and low level of vocational and scientific qualification for poor and unemployed women, and the results of poverty and its effects on women require working with clear policies To confront it on the general social level and among women in particular, the Takaful Coordination Authority / 2010 / Analysis of the reality of poverty in the Hashemite Kingdom of Jordan.

Jordan, like other countries, has gone through many economic crises that started since the beginning of the economic recession and reflected on the increase in the size of unemployment, the decrease in employment opportunities, and the increase in the poverty rate among members of society. As women wanting to work became convinced that the labor market does not provide decent opportunities, and they moved to the list of economically inactive women, which affects the achievement of the sustainable development goals of 2030, as the proportion of the workforce among women decreased according to 2019 figures during the third quarter to reach 13.2\%. Report of the case of women and men Jordan Population in Jordan 10309000 people (Department of Statistics, Statistical Book, 2017).

The relative distribution of the population by sex was $47.1 \%$ for females and $52.9 \%$ for males (Department of Statistics, Statistical Book, 2017) and the family by sex of the head of the household up to 2017 was $87.7 \%$ male and $12.2 \%$ female Singles for males 59.1 and 39.8 females, and for married couples, 40.3 males and 55.8 females, according to the Population and Family Health Survey 2017/2018, Department of Statistics. 
The unemployment rate for males in 2018 was $16.5 \%$, while for females, $26.8 \%$, the Department of Statistics, annual data for the Employment and Unemployment Survey Benefit according to the gender of the head of the family from the aid fund $1.27 \%$ and $5.93 \%$ males, Department of Statistics, Family Income and Expenditure Survey for the $2016 / 2017$ years.

Hence the importance of this study to identify the social problems facing poor women: a study on women benefiting from the aid fund in the Ruwaishid area.

\section{The importance of studying:}

The importance of the study is shown below:

- Lack of studies at the local level that dealt with the topic of poor women and the social problems that they are exposed to despite its importance and its impact on society in general and an important segment which is the woman who is half of society and an important pillar in the field of its development, which makes it necessary to have such a study to enrich the scientific library for researchers.

- Knowing the social problems of the poor woman will contribute in helping decision-makers to develop programs that contribute to solving their problems, and therefore this will be positively reflected on the family and society.

\section{Objectives of the study:}

The study seeks to achieve the following goals:

1. Learn about the social problems of the poor woman related to the woman herself.

2. Learn about the social problems of the poor woman related to her family.

3. Learn about the social problems of poor women related to society and gender.

4. Identify the varied responses of the respondents according to their social and economic characteristics.

\section{Study questions:}

The study came to answer the following questions:

1. What are the social problems of the poor woman related to the woman herself?

2. What are the social problems of the poor woman related to her family?

3. What are the social problems of the poor woman related to society and gender?

4. What is the variation in the respondents' answers according to their social and economic characteristics?

\section{Study concepts:}

5.1 Poor women: A woman who does not have the financial and social ability that qualifies her to access the resources available in her community so that she can live in dignity within an adequate standard of living, whether she lives alone or with her family (Jabr, 2009).

5.2 Social problems: In view of the lack of consensus from sociologists on a specific definition of social problems, and for the purposes of this study, the Weinberg definition was adopted, which states: They are behavioral patterns or situations that are rejected or undesirable by a large number of members of society, and these members recognize the need to formulate plans and programs and provide corrective services in confronting these problems and limiting their effect.

\section{National Aid Fund:}

The National Aid Fund aims to provide protection and care for needy families, raise their standard of living, and contribute to activating the skills of their members and developing them, developing their capabilities and integrating them in the labor market to ensure the family has continuous income and converting its members into aid providers instead of being eligible for it, by providing monthly and emergency aid Aids for physical rehabilitation, and provision of vocational training and employment programs for children of needy families. The Fund also provides its services in the field of recurring monthly aid to approximately 90,000 families, which constitutes $7.5 \%$ of the population of the Kingdom.

The financial statements of the National Aid Fund show that the total expenditures reached 3.3 million dinars in 2019 , an increase of $2.7 \%$ over the year 2018 according to the data of the general budget for 2019 (the state budget 2020 prospects and solutions 2019.

\section{Theoretical framework for the study:}

There are many different feminist theories that have attempted to monitor the different aspects of the disparity 
between men and women in human societies and what these theories aim at is to focus on the conditions of women and make them at the forefront of the social problems that societies face so that they are not dealt with as a sub issue within social theories, which makes them Gaining attention befitting the place of women in human societies.

In the light of this study, we will address the forms of social inequalities between men and women in the light of the theoretical determinants that they involve and in light of the visions they provide that help to explain and analyze the social conditions that are restrictive to them and support their exploitation and devote their poverty and the most important:

\subsection{First: liberal feminism}

The liberal feminist movements emphasized the principle of the rationality of women and the necessity of obtaining equal education for men, in order to assure them of the mental ability of women and that they are eligible to demand education and work to get out of their poverty. The economic conditions that forced her out of school (Dear, 2005)

In its treatment of the social inequalities faced by women, it criticizes the inequalities based on biological differences and considers that they are not significant in order to establish differences in their rights and that it is unreasonable to justify the differences between men and women and take advantage of these negative perceptions in perpetuating differences at the level of joining the labor market and the related Income disparities on the one hand and obtaining higher positions on the other hand, and despite the successes achieved by the liberal theory in supporting women to enter the labor market, they were less successful in eliminating other forms of discrimination (Abdel-Azim, 2014)

\subsection{Second: Radical Feminism}

She pointed out that the man in the patriarchal society controls his customs and uses biological differences to confirm the oppression of women in what is called the patriarchal system. The patriarchal ideology has exacerbated the biological differences between men and women when it made the roles of hegemony belong to the man and made the dependency roles the share of women, so men control women, so the poor woman is subject to the pressure of the husband Society, and the man exploits women to depend on free domestic work, and if the husband leaves, the burden becomes on the poor woman, and her suffering begins by society.

The owners of the struggle trend see that the social problems that poor women suffer from are mainly due to class mechanisms and among these problems the problem of male domination and the problems of gender inequality go back to the patriarchal social structure where human culture confirms the reproduction of the roles of women.

The conflict theory holds that the economic problems facing a poor woman are the reason for its dependence on men and its low status, and increasing the burden on the poor woman in the event of the husband's departure (AlAdayleh, 2014).

\section{Related studies:}

The study of the Coordination Committee for Social Solidarity (2010) entitled: "Poverty of Women in Jordan: Characteristics and Processes Generating it" The study aimed to identify the causes of poverty for a woman's income, which were related to various surrounding circumstances, whether objective or self, with the aim of working to describe, interpret, predict and predict and be able to control it, Which was applied to a sample of 739 families headed by a woman, of which 633 families receive cash aid from the National Aid Fund and 106 nonpoor families using the corresponding questionnaire, The study reached a number of results, the most important of which is that one of the most important reasons that led to the poverty of women who head families is the death of the breadwinner of the family, followed by the absence of the breadwinner and the extent of their taking of the diversity of sources of family entry and spending, and that the most important problems experienced by the poor woman is the occurrence of violence on her, her exposure to divorce, The absence of her own income, the deterioration of her health.

Al-Adayleh study (2014) entitled "Social-psychological problems of poor women in urban margins". The study aimed to show the social and psychological problems of poor women related to their social status and future expectations, methods they create for their children and their gender-related problems, and to identify the impact of qualitative changes in the problems experienced by women The poor The study showed that the poor woman has clear challenges towards her future expectations and has problems securing her children's material, moral and psychological requirements.

A Gabr (2015) study entitled "The Mechanisms of Adapting Poor Urban Women: A Sample Study of Women 
Beneficiaries of the National Aid Fund in the Blue Reed" The study aimed to identify the mechanisms of adapting poor urban women to meet their needs and the basic needs of their family and reveal their social, economic and health characteristics The study relied on the social survey method in Al-Ain for poor women whose families receive cash aid from the National Aid Fund office in the Casbah, Zarqa Governorate. As the sample size of the study reached 136 poor women, who constituted $3.8 \%$ of the study population, and the results showed the diversity of the coping mechanisms used by poor urban women and their dependence mainly on socially acceptable adaptation mechanisms such as rationing in consumption, reducing spending and optimal investment of resources and some other mechanisms that are socially unacceptable, such as the absence of investment in resources Humanity.

The Kafawain study (2015) entitled "The problems facing women who head poor families: a field study on a sample of the benefits of the National Aid Fund" The study aimed to know and understand the most important problems facing poor women in depth and the researcher used the qualitative approach and the study showed that the most important problems that They expressed poverty, physical, health, educational, social and psychological poverty, as well as domestic violence, and that most of the women in the sample knew some kind of violence during their marital life, and their interpretations of the reasons for these problems and the ways in which they dealt with them varied.

Abu Haidar study (2010) entitled "Pockets of Deprivation and Poverty in Jordan" The study aimed to identify the pockets of deprivation and poverty in Jordan in which there is a focus for disadvantaged families, in addition to identifying the relationship between the different dimensions of deprivation on the one hand and the relationship of these dimensions with income poverty on the one hand Others, and providing decision-makers at the higher level with an objective criterion for determining the priorities of development intervention in the governorates and within each governorate, and thus contributing to reducing the development disparities between the governorates, and the study reached a set of results, the most important of which is that the percentages of disadvantaged families according to the compound deprivation index reached $(27.7 \%)$, which Done It is similar through deprivation evidence for the five fields (education, housing, infrastructure, use, ownership of assets, durable goods).

Tebele and Catherine Study (Tebele, 2011): A case study of a poor widow woman living in South Africa through an in-depth interview conducted over a period of ten weeks. Gender.

Joshi study (2004) entitled: Women's Headship of Women in the Countryside of Bangladesh "Characteristics of Households Headed by Women and the Impact of this Presidency on Educating Children" The results showed that the family headed by a widow who are more vulnerable to poverty and less ownership of assets and that children in families headed by women Widows are more likely to work outside the home compared to children in maleheaded households

Study and Widjaja (Widjaja, 2009) A study titled "Microfinance is not for the Poor" The study aimed to discuss the effectiveness of microfinance in reducing poverty by discussing the pros and cons of microfinance institutions, and the mechanisms used to provide financing and reach solutions to the problems raised, and it was from The results of the study: Financing helps poor people get them out of poverty by increasing their income, and empowering women to be able to take appropriate decisions and improve their economic and social conditions, which is an effective way to create better educational, health and nutritional opportunities for their children, but many institutions do not reach the poorest of the poor, or exclude them because of discrimination from the institutions themselves, or the people responsible for them, Therefore, the study recommended the necessity of identifying the basic needs of these poor first and satisfying them, then building their capabilities through education and training, and thus they have sufficient confidence to obtain microfinance services.

\section{Study Approach:}

The comprehensive social survey method was used to achieve the goal of the study, which is to identify the social problems facing poor women: a field study on women benefiting from the aid fund in Ruwaishid area, to describe the research community and explain its characteristics and come up with a set of results.

\subsection{Study population and sample:}

The study population consisted of all the poor women whose families receive cash aid from the office of the National Aid Fund in the Ruwaishid area in Mafraq Governorate, and they numbered (164) women, according to the records of the National Aid Fund 2019, who met the conditions for obtaining the cash aid as the National Aid Fund was provided. Excluding (3) questionnaires for not being valid for statistical analysis purposes, as the final sample consisted of (161) women. 


\subsection{Study tool:}

The questionnaire was relied upon as a main tool for collecting data. The questionnaire was designed to achieve the goals of the study and included two axes. The first axis includes the characteristics of the study sample and the second axis. It included the most important problems facing women themselves, their family and their community.

\section{3 honesty and persistence:}

The validity of the tool was confirmed using the method of consensus of the arbitrators, as it was presented to a group of professors specialized in sociology to ensure the accuracy of its cognitive and methodological construction. High value and acceptable for the purposes of the application of the study.

\section{The Results;}

The social problems of poor women who head their families, who are beneficiaries of the National Aid Fund in the Ruwaishid region, ranged between (3.46 and 3.43), where the problems generally have a total arithmetic average of (3.45), which is from the middle level, and it came in The first rank is both (problems facing poor women related to themselves, and problems facing poor women related to the family), and these two dimensions have the highest arithmetic average of (3.46) and a standard deviation (0.65 and 0.67) respectively and they are from the middle level, and secondly The problems faced by poor women related to society $\mathrm{P}$ and gender, with an mean of (3.43) and a standard deviation (0.65), which is of the mean level.

\section{Recommendations:}

Depending on the previous results, this study provides a number of recommendations:

- Expanding the services and programs provided to poor women and facilitating their access to them throughout Jordan, such as productivity enhancement programs, small projects, and vocational training programs, etc.

- Providing psychological and social support programs for poor women and their children through cooperation with civil society organizations in all parts of Jordan and taking advantage of psychological counselors in schools.

- Conducting more qualitative studies specialized in the field of poor women to identify other problems that poor women suffer in Jordan in addition to social problems.

- Implementing numerous awareness campaigns in the media, including many experts, clerics and media professionals, and directed within the community in cooperation with civil society organizations to change the stereotypical view of the poor woman in society and its children.

- Take advantage of institutions and companies in the private sector to provide initiatives to employ poor women within conditions and a suitable environment safe for work.

- Establish a national strategy to protect poor women, with specific goals and implementation points, to help poor women break the cycle of poverty and get out of the problems they face because of it.

\section{Reference}

Adayleh, L. (2014), Socio-psychological Problems of Poor Women in Urban Margins, Jordanian Journal of Science, Volume 7, No. 1, Amman, Jordan.

Abu Haider, A. (2010), Pockets of Deprivation and Poverty in Jordan, "A Study Based on a Multidimensional Approach to Measuring Poverty," PhD thesis, University of Jordan, Amman, Jordan.

Abu Farash, H. (2010), The Demographic, Social and Economic Characteristics of Jordanian Families Headed by a Woman and the Problems They Face, University of Jordan, Arab Women Center for Training and Research: Amman, Jordan.

Department of Statistics (2013), Poverty Assessment Report in Jordan, Amman, Jordan.

Department of Statistics (2008), Women and Men in Jordan, Figures 2008, Amman, Jordan.

Al-Laithi, H. (2004), Policies to Fight Poverty and Inequality Based on Gender in the Region, the Arab Regional Forum for Population, the League of Arab States, the United Nations Population Fund and the Economic and Social Commission for Western Asia, Beirut, Lebanon.

The Economic and Social Council, the state budget 2020, prospects and solutions for 2019, Amman, Jordan. 
The Social Solidarity Coordinating Authority (2010), Women's Poverty in Jordan: Characteristics and Processes Generating it, Amman, Jordan.

Wishah, A. (2009), The Poor Family Headed by a Woman: A Study of Facts and Family Processes Generating Poverty, Unpublished PhD thesis, University of Jordan, Amman, Jordan.

Jabr, R. (2010), The role of the social safety net in protecting poor Jordanian women, PhD thesis, University of Jordan, Amman, Jordan. 